\title{
General Procrastination Scale: Development of Validity and Reliability
}

\author{
Pragya Lodha', Ahana Sharma', Gale Dsouza', Ishwari Marathe', Shanaya Dsouza', Shivani Rawal', Vidhi \\ Pandya ${ }^{1}$, Avinash De Sousa ${ }^{2, *}$
}

\section{Pragya Lodha ${ }^{1}$, Ahana Sharma', Gale Dsouza', Ishwari Marathe', Shanaya Dsouza', Shivani Rawal', Vidhi Pandya ${ }^{1}$, Avinash De Sousa ${ }^{2, *}$}

${ }^{1}$ Clinical Psychologist and Former Post Graduate Student, Maniben Nanavati Women's College, Mumbai, Maharashtra, INDIA.

${ }^{2}$ Consultant Psychiatrist, Desousa Foundation, Mumbai, Maharashtra, INDIA.

\section{Correspondence}

Dr. Avinash De Sousa,

Consultant Psychiatrist, Desousa Foundation, Carmel, St. Francis Road, Off SV

Road, Santacruz West-400054, Mumbai, Maharashtra, INDIA.

Phone no: +91 2226460002

Email: avinashdes888@gmail.com

History

- Submission Date: 04-04-2019

- Revised Date: 10-10-2019

- Accepted Date: 31-10-2019

DOI : 10.5530/ijmedph.2019.3.19

Article Available online

http://www.ijmedph.org/v9/i3

\section{Copyright}

(C) 2019 Phcog.Net. This is an openaccess article distributed under the terms of the Creative Commons Attribution 4.0 International license.

\begin{abstract}
Background: Procrastination, generally out, is the practice of carrying out less urgent tasks in preference to more urgent ones, or doing more pleasurable things in place of less pleasurable ones and thus putting off impending tasks to a later time. The primary objective of this paper was to establish preliminary psychometric properties of General Procrastination Scale (GPS)- validity and reliability. The scale. Methods: The final version of GPS was administered on a randomized sample of 140 participants, 69 males and 71 females between the age group of 16 to 27 years. The target population included college students and working younger adults across various regional subdivisions of the metropolitan city of Mumbai. The sample of the test was selected via a Non Probability sampling method of Quota Sampling. Results: The Split Half Reliability was calculated equivalent to 0.711 , which was similarly close to the value of Cronabch's Alpha correlation value, established at 0.714. The General Procrastination Scale was observed to be high on construct validity $(0.76)$ when compared with performance on Lay's scale of Procrastination. The quartile deviation value was obtained to be 8 and 3 inter quartile ranges were developed for the scale- Q1- 59, O2- 66 and O3- 75, where Q2 is equivalent to the median/mean of the scores on the scale. Conclusion: The test is a first of its kind, having been developed and standardized in a relatively collectivist culture and yet in a fairly modernized geographical region, opening grounds for greater research on cross cultural study of procrastination. The scale however has not been standardized on a statistically sufficient large sample of population.

Key words: Procrastination, Scale, Young, Validity, Reliability.
\end{abstract}

\section{INTRODUCTION}

Procrastination, generally out, is the practice of carrying out less urgent tasks in preference to more urgent ones, or doing more pleasurable things in place of less pleasurable ones and thus putting off impending tasks to a later time. In order for behaviour to be classified as procrastination: It must be counterproductive, needless and delaying. Similarly, it is to voluntarily delay an intended course of action despite expecting to be worse off for the delay.

Procrastination defined by Schraw, Wadkins and Olafson is a prevalent and pernicious form of selfregulatory failure that is not entirely understood. It is defined as unnecessarily postponing or avoiding tasks that must be completed. ${ }^{1}$ Clarry Lay defined procrastination as "a temporal gap between intended behaviour and enacted behaviour." That is, procrastination is occurring when there's a significant time period between when people intend to do a job and when they actually do it. It's estimated that about $15-$ 20 percent of the general population are procrastinators. ${ }^{2}$ Other researchers believe that procrastinators have less confidence in themselves, less expectancy that they can actually complete a task. Other predictors of procrastination include: task averseness, impulsiveness, distractibility and how much a person

Cite this article : Lodha P, Sharma A, Dsouza G, Marathe I, Dsouza S, Rawal S, Pandya V, Sousa AD. General Procrastination Scale: Development of Validity and Reliability. Int J Med Public Health. 2019;9(3):74-80. is motivated to achieve. Not all delays can be considered as procrastination; the key is that a person must believe it would be better to start working on given tasks immediately, but still not start. Further predictors of procrastination include: task aversion, impulsiveness, distractibility and how much a person is motivated to achieve. ${ }^{3}$ Timothy Pychyl says that people think of procrastination as an irrational delay because the reasons for action simply aren $t$ sufficient to motivate action. ${ }^{4}$ More accurately, procrastination is a-rational, without reason-because the real issue is emotional. Although we may know intellectually what we ought to do right now, we don't feel like doing it. So, we focus on short-term mood repair. He believes there are three basic reasons why people procrastinate. We most commonly procrastinate on things we find aversive. We put off things we don't like to do or that upset us in some way. Except that in life, we regularly face tasks we'd rather not do but really have to do.

\section{Selects Aspects of Procrastination Literature}

Besides, there is a huge pool of research literature that delineates on further aspects of procrastination with

che 
different socio-demographic variables. The following section discusses various studies that have been carried out globally in order to measure and understand procrastination as a construct.

A meta-analytical study studied procrastination's possible causes and effects, based on 691 correlations. ${ }^{3}$ It revealed that neuroticism, rebelliousness and sensation seeking show a weak connection with procrastinators. Strong and consistent predictors of procrastination were task averseness, task delay, self-efficacy, impulsiveness, conscientiousness and its facets of self-control, distractibility, organization and achievement motivation. These effects prove consistent with temporal motivation theory which is an integrative hybrid of expectancy theory and hyperbolic discounting. The procrastination levels of all the participants was measured by administering Aitkin's Procrastination Inventory.

In a study attempting to work with global numbers, researchers conducted an epidemiological study to determine the characteristics of prototypical procrastinators. ${ }^{5}$ They used a global sample based on the self - reported demographic variables like age, sex, marital status, education and nationality. Using an internet sampling strategy 16413 English speaking adults ( $58.3 \%$ women, $41.7 \%$ men: $M$ age $=38.8$ years, $S D=14$ ) were surveyed and it was found that procrastinators tended to be young, single men with less education, residing in countries with lower levels of self-discipline. Procrastination tended to mediate the relationship between sex and education providing support that men are lagging behind women academically because of lower self-regulatory skills.

Research has shown that procrastination, throughout, has been seen as a red flag or in combination with budding signs mental disorders such as anxiety, depression etc.

In a study conducted on Dysfunctional Procrastination and its Relationship with Self Esteem, Interpersonal Dependency and Self Defeating Behaviours (November 1994), young adults (202 women, 61 men) completed measures of decisional and behavioural procrastination, selfesteem, interpersonal dependency and self-defeating behaviour. ${ }^{6}$ Correlational analysis indicated that both procrastination types separately and combined were significantly related to low self-esteem, dependency on others and defeating behaviours. Among specific self-defeating behaviours, decisional procrastination was related to failing to complete crucial tasks, inciting anger in others and rejecting good-spirited others. Behavioural procrastination was related to failing task completion, rejecting well-minded others, feeling guilty after a positive event and choosing handicapping situations. These results suggest that types of procrastination may be predicted by similar personality factors and that chronic procrastination is dysfunctional toward achieving life goals.

In a research study on procrastination in students, a conflicting relationship between student procrastination and three academically related measures of personality: Perfectionism, locus of control a perceived stress was measured. ${ }^{7}$ The study also examined the relationships in a longitudinal assessment. 213 first year undergraduate students, (146 males and 67 females) completed the Aitken's Procrastination inventory, the multidimensional perfectionism scale and the academic locus of control scale within the first four weeks of the semester and then once again a week before the end of the university semester examination period. High procrastination at the start and end of the semester was related to external academic locus of control. Stress and socially prescribed perfectionism had little relationship with levels of procrastination. Only academic locus of control was elevated at the end of the semester as compared to the start of the semester.

Procrastination, as seen from the above-mentioned studies, is found to be an almost universal phenomenon among university students and reported to be associated with unsatisfactory academic performance and higher levels of stress and anxiety. Based on previous studies correlating academic procrastination to self-related variables like self-regulation, self-efficacy and self-esteem, Klassen and others, conducted a series of two studies to investigate the correlation of procrastination in two culturally diverse contexts- Canadian and Singaporean; and describe behaviours associated with procrastination, while also attempting to examine academic and motivation profiles of negative procrastinators, that is, those who report that procrastination negatively influences academic functioning. ${ }^{8}$

This relationship between academic performance and procrastination was also validated in the Indian context in a study. Among $209 \mathrm{sec}-$ ond-, third- and fourth-year undergraduate dental students of Bapuji Dental College and Hospital, Davangere, India, administered with the 16-item procrastination scale, it was found that students who showed high procrastination scores performed below average in their academics. Moreover, a significant difference in procrastination scores between the two gender groups $(p<0.05)$ was found. ${ }^{9}$ Hence, among the Indian undergraduate dental students, it was found that individuals with above average and average academic performance had lower scores of procrastination and vice versa.

In a study, 1,418 participants were administered with Tuckman's 16item procrastination measure and two components of the Motivated Strategies for Learning Questionnaire (MSLQ), to investigate the relationship of self-reported procrastination and academic self-efficacy, self-regulation, self-efficacy for self-regulated learning and self-esteem was studied. ${ }^{10}$ It was found that in both contexts, procrastination was significantly correlated with all of above-mentioned variables, with the strongest correlation observed between procrastination and self-efficacy for self-regulated learning. Moreover, students who rated their procrastination higher we observed to have lower GPAs in both contexts. Thus, no cultural difference was found.

In another part of the same study, the main objective was to investigate any cross-cultural differences that may exist, firstly, daily procrastination, that is, the hours of procrastination in a typical day; secondly, avoidance tasks, that is, the types of academic tasks most prone to procrastination; thirdly, the replacement activities students engage in when delaying academic tasks; and lastly, the perceived negative impact of procrastination on academic functioning. 389 Canadian (not overlapping with Study 1) and 337 Singaporean undergraduate students completed a survey measuring all the above aspects, mostly on a 7-point Likert scale, along with an estimate of the GPA and self-efficacy for self-regulated learning measures, of each participant. Results showed an average of less than $2 \mathrm{hr}$ of daily procrastination with no significant difference in both the cultural contexts. ${ }^{10}$ Moreover, in both contexts, writing was reported to be the academic task most prone to procrastination. In both contexts however, no correlation was found between the replacement activities. More Singaporean than Canadian students were found to be classified as negative procrastinators and, in every context, these negative procrastinators spent more time procrastinating than neutral procrastinators and additionally displayed lower self-efficacy for self-regulated learning.

Interestingly, Procrastination is seen to be related to the Big 5 Model in the following manner, with relationships found with Openness to Experience, Agreeableness, Extraversion and Conscientiousness. ${ }^{11}$

Openness to Experience: It is related to culture, intellect, need for cognition, vivid fantasy, artistic sensitivity, depth of feeling, behavioural flexibility, intellectual curiosity and unconventional attitudes), it shows the strongest relationship with intelligence and scholastic aptitude. ${ }^{12}$

Agreeableness: Rebelliousness, hostility and disagreeableness are thought to be major motivations for procrastination. ${ }^{13}$ Those with these personality traits are more likely to experience externally imposed schedules as aversive and thus to avoid them. By delaying work and starting it on one's own schedule, one also reasserts one's autonomy. The possibility of this ethology has led to the development of paradoxical treatments; 
for example, people are directed to procrastinate and when they rebel against this directive, they start work early. ${ }^{3}$

Extraversion: It is one of the more interesting possible causes of procrastination, but also one of the more complicated. Extraverts are usually described as sociable, optimistic, outgoing, energetic, expressive, exciting and impulsive. ${ }^{3,4}$ Typically, impulsiveness indicates spontaneity and a tendency to act upon whims and inclinations. Although pessimism and low energy level are aspects of depression, they are also a central part of extraversion, especially as measured by positive emotionality or affect. ${ }^{14}$ These preliminary findings demonstrate some of the complexities of extraversion, as procrastination's hypothesized relationships with these facets conflict. Both lethargy and impulsiveness are expected to predict procrastination, but lethargy indicates a lack of extraversion, whereas impulsiveness suggests an abundance of the trait. In keeping with this inconsistency, no significant results are expected for extraversion.

Conscientiousness: Procrastination is conceptually representative of low conscientiousness and self-regulatory failure. That each of these constructs represents low conscientiousness or self-regulatory failure is reviewed in the following, as is their theoretical connection to procrastination.

\section{Other Scales on Procrastination}

The intention-action gap refers to the degree to which people follow up on their original work plans. Most procrastination researchers suppose that delaying is not only irrational but also unintentional. They believe that procrastinators do not purposefully put off their chores, but do so to the contrary of their original intent-an "is" versus "ought" scenario. Failing to act upon one's intentions is quintessentially self-regulatory failure, almost the definition of low self-control. These researches incorporate scales measuring procrastination and its different facets, here are a few more scales measuring similar constructs:

1. Bruce Tuckman developed a 16-item procrastination scale as a self-report measure of procrastination tendencies. Tuckman chiefly wished to investigate the relationship of these tendencies to a behavioural measure of procrastination and to a self-report measure of general self-efficacy. The scale includes items like "I needlessly delay jobs, even when they're important," and "I always finish important jobs with time to spare.", wherein the possible responses range from 1: "That's me for sure," to 4: "That's not me for sure." On this summative scale, the lowest score between the ranges of 16 to 64 indicates greater procrastination tendencies. Items 7, 12, 14 and 16 are reverse scored, on this scale. The development of the scale included a pilot study of a 72-item scale, requiring responses in a 4-point Likert-type format that was administered to 50 college juniors and seniors. A factor analysis of the results yielded two factors which formed the basis for reducing the scale to 35 items with a resulting reliability of .90 . This 35 -item instrument then yielded a correlation coefficient of -.54 with performance on a self-regulated performance task called the Voluntary Homework System (VHS) and a correlation coefficient of -.47 with the General Self-Efficacy Test (GSE), both correlations of $p<.001$. In a subsequent study of 183 college students, a factor analysis of scores on the 35-item scale yielded a single-factor structure and a condensed scale of 16 items with a reliability of .86 . This final shortened version of the procrastination scale was recommended for use as a means of detecting students who may tend to procrastinate in the completion of college requirements. ${ }^{15}$

2. A Procrastination Assessment Scale for Students was developed by Solomon and Rothblum in 1984 is a 12 -item five-point Likert-type scale that measures the frequency with which students procrastinate on specific types of academic tasks, including term papers, examinations and reading assignments. It is a 12 -item scale. Possible scores on the PASS range from 12 to 60 , with higher scores indicating a greater tendency to procrastinate. An internal consistency estimate of 0.84 for the PASS on a sample of 135 graduate students and total scores has been found. They correlate positively with measures of depression and irrational cognitions and negatively with measures of self-esteem and punctuality. ${ }^{16}$

3. Costa and McCrae's Self-Discipline Scale, a facet of conscientiousness, contains several items strongly reminiscent of procrastination itself (e.g., "I waste a lot of time before settling down to work"). Similarly, as Schouwenburg concludes, "various studies show a very distinct clustering of related traits: trait procrastination, weak impulse control, lack of persistence, lack of work discipline, lack of time management skill and the inability to work methodically. ${ }^{17}$ In this constellation, there seems little justification for viewing procrastination as a separate trait. It is possibly more fruitful to label this cluster as (lack of) self-control"

4. A similar scale called The Academic Procrastination Scale (APS) authored by Justin. D. McCloskey has 25 items and was based on six different characteristics of procrastinators: Psychological belief about abilities, distractions of attention, social factors, time management skills, laziness and personal initiative. ${ }^{18}$ The APS has exhibited a high reliability, $\alpha=.95$. Nevertheless, reliability was extremely high. The APS was validated using 86 undergraduates consisting of diverse academic majors and years of college completion. Items were scored using a 5-point Likert-type scale where 1 indicates disagree with the item and 5 indicates agree with the item.

5. An Irrational Procrastination Scale (IPS) has been assessed and validated with the use of global sample in "Arousal, avoidant and decisional procrastinators: Do they exists" utilizing the internet sampling method using the 16,413 adults in eight speaking countries (58.3\% woman, $41.7 \%$ men) with age mean and standard deviation of 38.3 and 14 years revealing procrastination tendency associated to variables like age, gender, marital status, education and nationality. It correlates with the pure procrastination scale at 0.96 .

The present test construction focuses to measure the similar construct of procrastination. Titled, 'The General Procrastination Scale', it is a 23item scale that aims to measure procrastination in the Indian context, with the target population being young adults between the age group 17-27 years. On a 5-point Likert scale, the General Procrastination Scale taps four domains where an individual is likely predicted to procrastinate- academic performance, workplace situations, civic responsibilities and medical attention.

\section{Methodology}

\section{Sample}

The final version of GPS was administered on a randomized sample of 140 participants, 69 males and 71 females between the age group of 16 to 27 years. The target population included college students and working younger adults across various regional subdivisions of the metropolitan city of Mumbai- South Mumbai, Suburban Mumbai, Central Mumbai and Navi Mumbai. The regions were selected to include diversity of population across the regions of Mumbai.

\section{Sampling Method}

The sample of the test was selected via a Non Probability sampling method of Quota Sampling. This Quota Sampling method was used primarily for the sake of cost effectiveness, considering the fact that researches lacked any kind of financial backing. The sampling method was so selected also for the benefit of covering a targeted sample of 140 participants with ease of access and convenience. 


\section{Data Collection Tools}

All participants were administered with two scales, measuring an identically conceptualized construct of procrastination. There were two tools of data collection used in the present test construction, namely- Lay's Scale of Procrastination, which is a previously standardized and fairly popular scale to measure general procrastination, developed by C. Lay in 1986 and the General Procrastination Scale, developed by Lodha and others in 2016. Lay's Scale of Procrastination was used in order to establish construct validity of the current scale being constructed (GPS), while the other was the General Procrastination Scale being developed and presented by the above-mentioned co-authors.

\section{Procedure}

The test construction process began with the general conceptualization of the construct of procrastination, aimed to be measured by the test co-authors, based on which an item pool of 65 items was created, using a few items from older tests measuring the same or similar construct, rewording certain items and largely generating newer items, suitable for the present test.

The initial 65 items intended item pool was then handed over to 12 experts, by the test authors. These experts were generally professionals who were currently and have been for a while, actively engaged in the field of psychology and psychological testing. The experts were individually required to rate each item, in the intended item pool, as either Essential (E), Important (I), Unimportant (U) for the final version of the test. Each item was subjected to an analysis of its content validity, that is, the extent to which that item did indeed unambiguously measure and was relevant to the overall construct measured by the test, using C.H Lawshe's Content Validity Ratio formula. Items, with positive CVRs were retained. The final number of retained items was GPS was 23 items with items between the CVR of +0.10 to +0.80 . Along with the simple ratings, several experts' qualitative feedback was obtained and implemented as required, to create the final scale.

A consent form, consisting of a small description of the scale and the general purpose of the research, along with the confidentiality of results clause, was attached at the beginning of the General Procrastination Scale and thereby each participant's informed consent was obtained before they completed the questionnaire.

Note: The test was administered with the instructions, "We, the students of MNWC are conducting a study for a college assignment, with the objective of exploring certain aspects of human behaviour. We request you to sign this document and fill in the required details before proceeding, confirming that you have willingly participated in this study.

You are requested to respond to each statement below, by putting a cross $(\times)$ for either "Never", "Rarely", "Sometimes", "Often" or "Always" alternatives, that best indicate your behavior concerning that statement. Respond to each statement with honesty, so as to obtain accurate results about your behavior. We assure confidentiality and anonymity of your information, restricted to this study."

The test with finalised items was selected to generate a set of standardized instructions by the test co-authors. The General Procrastination Scale was administered to each of the 140 participants, along with Lay's Procrastination Scale. The administration of the two scales was counterbalanced in order to reduce possible cofounding in results. Thus, for half of the participants, the Lay's Scale was administered first, followed by the currently developed General Procrastination Scale, while the opposite order was used for the other half of the participants.

While administration, extraneous confounding of noise levels and distractions were controlled in order to reduce the chances of confounding of test scores and results. A Procrastination Quotient (P.Q.) was calculated for every individual participant.

While the GPS generally takes about $10 \mathrm{~min}$ to complete, a stipulated time limit was not confined by the test co-authors.

\section{The General Procrastination Scale}

The final scale has 23 items, measuring, academic, workplace, medical and civic responsibilities related procrastination. All items are required to be rated on a 5 point Likert scale ranging from 1 to 5 .

Scores (Procrastination Quotient) of each item are calculated according to the following order:

$$
\begin{aligned}
& 1=\text { Never } \\
& 2=\text { Rarely } \\
& 3=\text { Sometimes } \\
& 4=\text { Often } \\
& 5=\text { Always }
\end{aligned}
$$

Items 5, 8, 12, 16, 18, 21 and 23 were reversed scored. Scores are obtained as a sum of response to each item and they range from 23 to 115 . A higher sum of scores obtained on all items indicates higher level of procrastination for the individual test taker.

\section{Lays Procrastination Scale}

The Lay's Scale is a 5 point Likert scale, consisting of 20 items, wherein for each item, response alternatives range from extremely uncharacteristic to extremely characteristic. ${ }^{19,20}$ Scores of each item are calculated according to the following order:

$1=$ Extremely Uncharacteristic

$2=$ Moderately Uncharacteristic

$3=$ Neutral

$4=$ Moderately Characteristic

$5=$ Extremely Characteristic

\section{Data Analysis Method}

A set of descriptive statistical procedures were performed on the obtained test scores Graph 1 and the following values were obtained for Standard Deviation (9.89), Test Variance (98) and Total Item Variance (31.25). The data obtained from the scores of the 140 participants were further used to carry out inferential statistical analyses that included the calculation of correlation values for validity and reliability scores for the GPS scale.

A Split Half Reliability coefficient was computed by correlating the two halves of the test, divided as odd and even items and later, adjusted with the Spearman- Brown adjustment formula. Item variance and total test

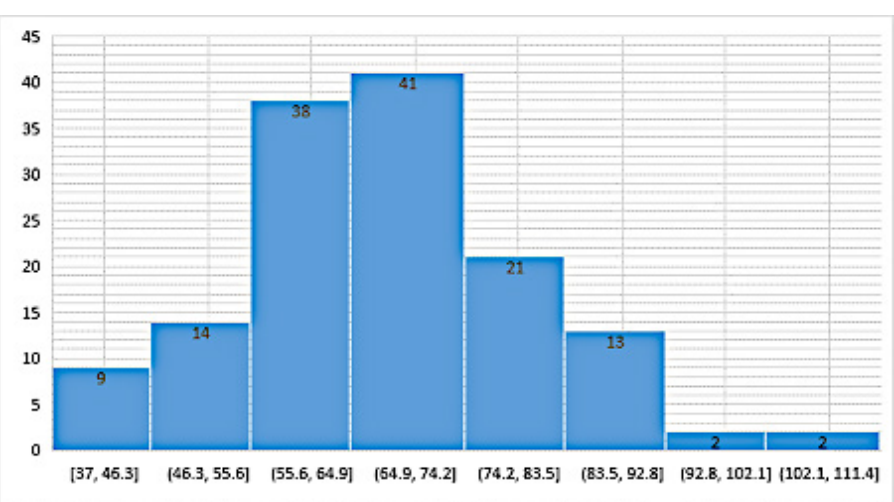

Graph 1: Distribution of scores as Bar graph. 
variance was computed using Microsoft Excel Spreadsheet. A Cronbach's Alpha coefficient was also computed to present evidence for test reliability.

As mentioned above, in the pre administration phase, Content validity was established using C.H Lawshe's Content Validity Ratio. Following data collection, Construct validity was established with the help of convergent evidence, by correlating the scores on the Procrastination Scale to scores of the participants on Lay's General Procrastination Scale.

A comparative study of the divergence in gender-based scores was also assessed to investigate the presence of gender differences in procrastination in the given sample.

Lastly, an inter-quartile range of the scores was obtained, along with the quartile intervals and the quartile deviation, depicting the extent to which scores deviated from the median. The inter-quartile range and quartile deviation was further graphically represented.

\section{Administration}

Consent must be taken before every participant before administration. The following instructions must be followed in order to administer the scale:

1. This is a scale that has 23 items and measures aspects of your daily thought processes and behaviours.

2. Read each statement carefully and give an honest response which holds true for you. There are no right and wrong answers.

3. Every statement has an answer key with 5 options. Make a cross $(\times)$ for either "Never", "Rarely", "Sometimes", "Often" or "Always" alternatives, depending on which option best indicate your behaviour.

4. There is no time limit to answer the scale but try to respond as fast as you can, without thinking too much before you respond.

\section{Psychometric Properties}

\section{Validity}

Content Validity or Expert Validity for the GPS was established through expert ratings on each item in the item pool (Table 1). Twelve experts in the field of Psychology, having a minimum qualification of a Master's Degree (M.A.) in Psychology, provided ratings for a total of 39 items in the item pool. Each item was rated as either "Essential", "Important but not essential" and "Unimportant" by each of the experts. The total number of "Essential" ratings for each item was calculated (ne) and the Content Validity Ratio (CVR) formula by C.H. Lawshe was applied to each item score as follows:

$\mathrm{CVR}=\frac{n e-N / 2}{N / 2}$

Where 'ne' is the number of experts who rated the item as essential and ' $\mathrm{N}$ ' is the total number of experts.

A total of 23 items were retained from the item pool, all of which had a positive CVR score ranging from 0.1 to 0.8 (such scores indicating that more than $50 \%$ of the experts agreed that the item was essential). Qualitative feedback was also taken into account.

Construct validity was established for the GPS scale, more specifically convergent construct validity. This was done by administering Lay's Procrastination Scale along with the GPS scale. The order of presentation of the two scales in succession was counterbalanced wherein half the test takers were given the GPS first and the other half of the test takers were given Lay's Procrastination Scale first. This was done to control for any fatigue effects or order effects on the results.

Total scores on each test for each test takers were calculated. A total of all the scores of all the test takers on the GPS as well as on the Lay's Procrastination Scale were calculated. These two total scores were correlated using Pearson's $r$ or Pearson's product moment correlation. A correlation of 0.76 was found between the scores on the two tests suggesting that there is high construct validity for the GPS.

Reliability

The internal consistency was assessed using the Split-Half method and Cronbach's Alpha.

The following steps were involved in the Split-Half method: The test was divided into 2 halves- odd and even items. A Pearson $r$ was calculated for the two halves. The half-test reliability was adjusted using the Spearman Brown Formula using the following formula

$r s b=\frac{n r x y}{1+(n-1) r \times x y}$

$=23^{\star} 0.097$

$1+(22) 0.097=2.231 / 3.134=0.711$

Thus, the reliability coefficient was 0.711

For Cronbach's Alpha, the formula used is as follows-

$\frac{\alpha=v\left(1+\sigma^{2}{ }_{1}\right)}{(v+1) \sigma^{2}}$

The reliability coefficient was 0.714 .

\section{Inter-quartile Range and Quartile Deviation}

Considering the scaling and scoring method used for the General Procrastination Scale, the range of scores was essentially 23 (if all items rated 1 or Never) to 115 (all items rated 5 or Always). The inter-quartile range for the sample of 140 participants was 59 to 75 , that is, the lower quartile Q1 was 59, the upper quartile Q3 was 75 and Q2 or the median of the range of scores was 66 .

The Quartile Deviation (QD) was calculated and a value of 8 was obtained for the same. Most participants scored between the ranges of 55.6 to 83.5 , that is, within the inter-quartile range and thus clustered around or not deviating largely, from the median.

The inter-quartile range was further also used by the test authors to set ranges of scores used to interpret an individual test taker's standing on the construct of procrastination, as measured by this scale.

These ranges are as follows:

The calculation of QD was as follows- (Table 3)

$\mathrm{QD}=\left(\mathrm{Q}_{3}-\mathrm{Q}_{1}\right) / 2$

$=(75-59) / 2$

$=16 / 2$

$=8.0$

\section{RESULTS}

The GPS, after having administered to 140 participants- 69 males and 71 females of population between the ages of 16-27 years, was found to have a fair reliability correlations. The Split Half Reliability was calculated equivalent to 0.711 , which was similarly close to the value of Cronabch's Alpha correlation value, established at 0.714 . The General Procrastination Scale was observed to be high on construct validity (0.76) when compared with performance on Lay's scale of Procrastination. The quartile deviation value was obtained to be 8 and 3 inter quartile ranges were developed for the scale- Q1- 59, Q2- 66 and Q3- 75, where Q2 is equivalent to the median/mean of the scores on the scale.

In addition, the scale has a median value of 3 , with standard deviation equivalent to 9.89 (Table 2). The highest individual score obtained on the General Procrastination Scale was a Procrastination Quotient (P.Q.) (Table 4) of 110 whereas the lowest obtained score was P.Q. 37; thus, a range of 73 was confirmed for the scale. 


\begin{tabular}{|c|c|}
\hline Item No. & CVR \\
\hline 1 & 0.5 \\
\hline 2 & 0.33 \\
\hline 3 & 0 \\
\hline 4 & 0.16 \\
\hline 5 & -0.33 \\
\hline 6 & 0.16 \\
\hline 7 & -0.16 \\
\hline 8 & 0.3 \\
\hline 9 & 0.3 \\
\hline 10 & 0.8 \\
\hline 11 & 0.6 \\
\hline 12 & 0.3 \\
\hline 13 & 0 \\
\hline 14 & 0.5 \\
\hline 15 & 0.66 \\
\hline 16 & 0.5 \\
\hline 17 & -0.33 \\
\hline 18 & 0.33 \\
\hline 19 & -0.5 \\
\hline 20 & 0.33 \\
\hline 21 & 0.17 \\
\hline 22 & 0.6 \\
\hline 23 & 0 \\
\hline 24 & -0.4 \\
\hline 25 & -0.2 \\
\hline 26 & 0 \\
\hline 27 & 0 \\
\hline 28 & 0.17 \\
\hline 29 & 0.17 \\
\hline 30 & -0.17 \\
\hline 31 & 0.67 \\
\hline 32 & 0 \\
\hline 33 & 0.5 \\
\hline 34 & -0.34 \\
\hline 35 & 0.34 \\
\hline 36 & -0.5 \\
\hline 37 & 0 \\
\hline 38 & 0 \\
\hline 39 & 0 \\
\hline 40 & -0.67 \\
\hline 41 & -0.67 \\
\hline
\end{tabular}

\begin{tabular}{cccc} 
Table 2: Statistical Values for GPS. & Test Variance & $\begin{array}{c}\text { Total Item } \\
\text { Variance }\end{array}$ \\
\hline Total No. Items & $\begin{array}{c}\text { Standard } \\
\text { Deviation }\end{array}$ & Test & 31.25 \\
\hline 23 & 9.89 & 98 &
\end{tabular}

Table 3: Inter-quartile ranges of GPS.

\begin{tabular}{cc} 
Quartiles & Value \\
\hline Q1 & 59 \\
Q2 (median) & 66 \\
Q3 & 75 \\
\hline
\end{tabular}

Table 4: Procrastination Quotient (P.Q.) values of GPS.

$\begin{array}{ccc}\text { P.Q. Value } & \text { Range } & \text { No. of participants } \\ 75 \text { and above } & \text { High } & 35 \\ 67 \text { to } 75 & \text { Above Average } & 33 \\ 60 \text { to } 66 & \text { Average } & 32 \\ 59 \text { and below } & \text { Low } & 40\end{array}$

\begin{tabular}{rcc}
\multicolumn{2}{c}{ Table 5: Psychometric Properties of GPS. } \\
Sr. No. & Psychometric Property & Value \\
\hline 1. & Pearson r & 0.097 \\
2. & Split Half Reliability & 0.711 \\
3. & Cronbach's Alpha & 0.714 \\
4. & Construct Validity & 0.76 \\
5. & Quartile Deviation & 8.0
\end{tabular}

Gender differences in the procrastination quotient were also observed where males (85.5) were observed to be high on procrastination as compared to females (78.5). (Figure 1)

\section{DISCUSSION}

With an intended item pool of 65 items to begin with and then 41 items, the General Procrastination Scale (GPS) was co-authored by Lodha et al. (2016). After having evaluated the scale qualitatively and through inter-rater judgements and calculation of Content Validity Ratio, the scale was finalised to have 23 items. The scale was administered to 140 participants- males and females to calculate a Procrastination Quotient for every individual participant. While administration, extraneous confounding of noise levels and distractions were controlled in order to reduce the chances of confounding of test scores and results. The GPS was administered along with Lay's Procrastination Scale. The two scales were counterbalanced and administered in order to ward off confounding as a result of administration.

A consent form, consisting of a small description of the scale and the general purpose of the research, along with the confidentiality of results clause, was attached at the beginning of the General Procrastination Scale and thereby each participant's informed consent was obtained before they completed the questionnaire

The GPS, a 23-item scale of procrastination has a descriptive median value of 3 , with standard deviation equivalent to 9.89. The highest individual score obtained on the General Procrastination Scale was a Procrastination Quotient (P.Q.) of 110 whereas the lowest obtained score was P.Q. of 37 ; thus, a range of 73 was confirmed for the scale. It was administered to 69 males and 71 females, who were within the age range of 16-27 years 


\section{Gender differences}

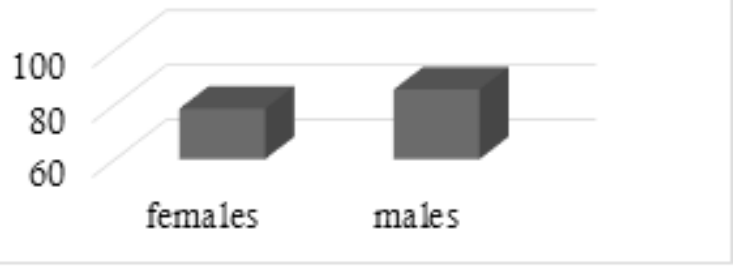

Figure 1: Gender differences in scores on GPS.

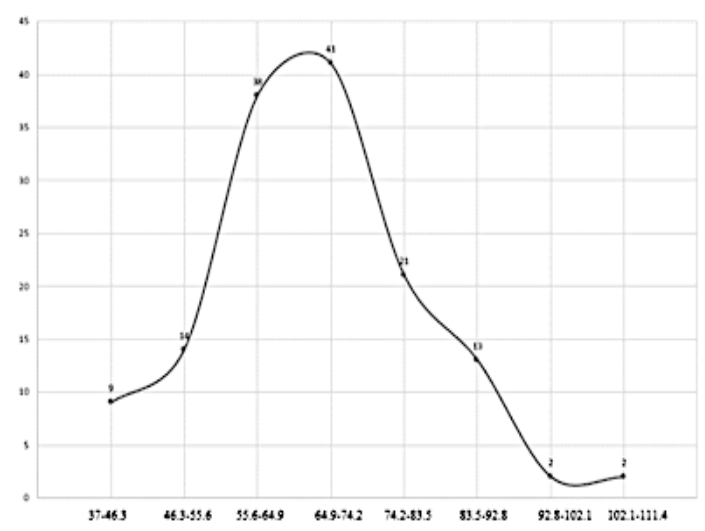

Graph 2: The total distribution of scores.

from various regions of the city of Mumbai. The data obtained from the scores of the 140 participants were further used to carry out inferential statistical analyses that included the calculation of correlation values for validity and reliability scores for the GPS scale.

Keeping in mind the obtained quartile deviation (8) and having confirmed 66 as the median value (Q2), the trend of scores obtained on the GPS show that out of 140 participants, 35 people were high procrastinators with scores falling above 75. Most participants (40) were low on procrastination with a score of below 59 on the General Procrastination Scale. Thirty-three individuals scored above average range of procrastination with their scores falling between $67-75$ and 32 participants were average procrastinators with a score between 60-66.

The psychometric properties of the scale were also developed. Content Validity (positive CVR values raging between 0.1-0.8) and Construct Validity (0.76); Split Half Reliability (0.711) and Cronbach's Alpha (0.714) along with Quartile Deviation (8) and Inter-quartile range were established for the GPS scale.

A gender difference in procrastination quotients was also calculated and results showed that males (85.5) in general were high on procrastination, as compared to females (78.5).

\section{Evaluation and Limitations}

The development of the GPS is duly is good addition to the already existing procrastination literature and scales. The scale however has not been standardized on a statistically sufficient large sample of population. Similarly, using a convenience sampling method could have further hindered the possibility of generalizing the results of the scale to the larger population.
Having mentioned that, the test is a first of its kind, having been developed and standardized in a relatively collectivist culture and yet in a fairly modernized geographical region, opening grounds for greater research on cross cultural study of procrastination. Moreover, it has indeed been found to have sound psychometric properties (Table 5) and relatively high construct validity, which is a necessary and sufficient condition to be considered a good psychological testing instrument.

\section{CONFLICTS OF INTEREST}

The authors declare that there are no conflicts of interest.

\section{ABBREVIATIONS}

CVR: Content Validity Ratio; GPS: General Procrastination Scale; PQ: Procrastination Quotient; QD: Quartile Deviation; APS: The Academic Procrastination Scale; IPS: The Irrational Procrastination Scale; MNWC: Maniben Nanavati Women's College.

\section{REFERENCES}

1. Schraw G, Wadkins T, Olafson L. Doing the things we do: A grounded theory of academic procrastination. J Educ Psychol. 2007;99(1):12-8.

2. Schouwenburg HC, Lay CH, PychylTA, Ferrari JR. Counseling the procrastinator in academic settings. American Psychological Association. 2006.

3. Steel P. The nature of procrastination: A meta-analytic and theoretical review of quintessential self-regulatory failure. Psychological Bulletin. 2007;133(1):65.

4. Pychyl TA. The procrastinator's digest: A concise guide to solving the procrastination puzzle. Xlibris Corporation. 2010.

5. Steel P. Arousal, avoidant and decisional procrastinators: Do they exist?. Personality and Individual Differences. 2010;48(8):926-34.

6. Ferrari JR. Dysfunctional procrastination and its relationship with self-esteem, interpersonal dependency and self-defeating behaviors. Personality and Individual Differences. 1994;17(5):673-9.

7. Towers AJ. Student procrastination: A clarification and longitudinal analysis of its relationship to perfectionism, locus of control and stress in university students: a research project presented in partial fulfillment of the requirements for the degree of Master of Arts in Psychology at Massey University, Palmerston North, New Zealand (Doctoral dissertation, Massey University). 2000;1-152.

8. Klassen RM, Ang RP, Chong WH, Krawchuk LL, Huan VS, Wong IY, et al. A cross-cultural study of adolescent procrastination. Journal of Research on Adolescence. 2009;19(4):799-811.

9. Lakshminarayan N, Potdar S, Reddy SG. Relationship between procrastination and academic performance among a group of undergraduate dental students in India. Journal of Dental Education. 2013;77(4):524-8.

10. Tuckman BW. The development and concurrent validity of the procrastination scale. Educational and Psychological Measurement. 1991;51(2):473-80.

11. Antonioni D. Relationship between the big five personality factors and conflict management styles. International Journal of Conflict Management. 1998;9(4):336-55.

12. McCrae RR. Social consequences of experiential openness. Psychol Bull. 1996;120(3):323-45

13. Aremu AO, Williams TM, Adesina F. Influence of academic procrastination and personality types on academic achievement and efficacy of in-school adolescents in Ibadan. IFE Psycholog IA: An International Journal. 2011;19(1):93-113.

14. Watson D, Clark LA. Extraversion and its positive emotional core. In Handbook of Personality Psychology. 1997;767-93. Academic Press.

15. Tuckman BW. The development and concurrent validity of the procrastination scale. Educ Psychol Measure. 1991;51(2):473-80.

16. Solomon LJ, Rothblum ED. Academic procrastination: Frequency and cognitivebehavioral correlates. Journal of Counseling Psychology. 1984;31(4):503.

17. JrCosta PT, McCrae RR. Personality assessment in psychosomatic medicine. Adv Psychosom Med. 1987;17:71-82.

18. Schouwenburg HC. Procrastinators and fear of failure: An exploration of reasons for procrastination. Eur J Personality. 1992;6(3):225-36.

19. McCloskey J. Academic procrastination (Doctoral dissertation, Thesis. University of Texas). 2012

20. Lay $\mathrm{CH}$, Schouwenburg HC. Trait Procrastination, Time Management. Journal of Social Behavior and Personality. 1993;8(4):647-62. 